\title{
O Uso da Fotografia na Educação Ambiental: Tecendo Considerações ${ }^{1}$
}

\author{
Larissa Souza da Silveira ${ }^{2}$ \\ Josineide Vieira Alves $^{3}$
}

Resumo: Este artigo investiga as contribuições da fotografia como recurso metodológico e educativo em Educação Ambiental para a formação de sujeitos participativos e atuantes no processo socioambiental. A revisão de literatura abrangeu desde pressupostos históricos importantes na consolidação do quadro ambiental atual, a visão de sujeito ecológico e a caracterização da educação ambiental crítica até a apresentação de um levantamento das metodologias utilizadas nessa área, destacando a fotografia como possibilidade iminente. Segue-se uma reflexão acerca da interface fotografia-educação ambiental, explicitando as vantagens dessa parceria teórico-metodológica para a formação de sujeitos sensíveis, críticos e atuantes na área ambiental.

Palavras-chave: Educação Ambiental Crítica, Sujeito Ecológico, Fotografia.

Abstract: This article investigates the contributions of photography as a methodological and educational resource within Environmental Education for the development of acting and participative people in the socioenvironmental process. The literature review included since important historical premises in the consolidation of the current environmental scenario - going deeper into the consolidation of environmental education in Brazil -, the view of a "green person", and the characterization of a critical environmental education, until the presentation of a survey of methodologies currently in use in that area, highlighting photography as an immediate possibility. A reflection on the interface between photography and environmental education is then presented, pointing out the advantages of this theoretical and methodological alliance for the development of sensible, critical and acting people in the environmental area.

Keywords: Critical Environmental Education, Green Person, Photography.

1 Artigo elaborado a partir de monografia apresentada à Universidade Salvador no ano de 2006 para a obtenção do título de bacharel em Psicologia.

2 Técnica na área de Educação Ambiental da Secretaria Municipal de Educação e Cultura de Salvador - BA, e psicóloga. Contato: R. Ministro Bulcão Viana, 03 - Bonfim, Salvador BA. CEP: 40415-070. E-mail: larissasilveira@hotmail.com .

3 Docente do curso de psicologia da Fundação Bahiana para o Desenvolvimento das Ciências e da Faculdade Ruy Barbosa. 


\section{Educação Ambiental: do conservadorismo moderno à criticidade contemporânea}

A intervenção dos seres humanos na natureza tem assumido uma proporção descontrolada, uma vez que tal processo se caracteriza pela utilização de práticas predatórias, que atuam diretamente na degradação do meio ambiente (CAMPOS, 2000).

De acordo com Grün (1996), a ética antropocêntrica é uma das principais responsáveis por essa degradação. Nela, os seres humanos se colocam como o centro do mundo; são capazes de dominar a natureza, utilizando-a da forma que julgarem conveniente para os seus interesses. Essa ética remonta aos tempos antigos, mas tem a sua consolidação a partir da filosofia de Descartes.

É com base nas idéias de Descartes que a oposição homemnatureza se consolida, formando o cerne do pensamento moderno (GONÇALVES, 2000). Para impor a sua autonomia, a razão cartesiana precisa exercer a dominação sobre um objeto, sendo este a natureza. Contudo, não há como dominar algo do qual se faz parte. Assim sendo, o homem se retira da natureza, transformando-a em seu objeto de estudo. Como aponta Grün (1996, p. 35), “o processo de objetificação implica simultaneamente domínio, posse, mas também perda, afastamento da natureza".

Com o desenvolvimento do capitalismo, a ética antropocêntrica chega às suas últimas conseqüências e a Revolução Industrial torna-se o cenário para o fortalecimento dessas idéias. $O$ trabalho, que antes era atividade essencial, visto que o cultivo das terras objetivava apenas a garantia do alimento pelos servos e camponeses, agora se torna atividade aquisitiva, visando à produção para a venda ao mercado (CAMPOS, 2000; GONÇALVES, 2000). Essas mudanças nos cenários político e econômico da sociedade agregam aos indivíduos novos valores e novos comportamentos que convergem para a ética capitalista. Tal ética, pautada principalmente no desenvolvimento econômico, suscita uma distribuição de renda cruel que determina um abismo entre as diferentes classes sociais.

Vale ressaltar que as dificuldades encontradas nas relações homem-natureza devem-se muito mais às relações humanas de forma 
geral, que se encontram cada vez mais desarmoniosas e emitem o seu reflexo no ambiente por meio da sua degradação. Os impactos ambientais vão além da poluição, das mudanças climáticas, da diminuição da biodiversidade: a sociedade vem apresentando sintomas de um modelo desenvolvimentista predatório e desmedido, como exclusão social, consumismo e perda da qualidade de vida (DIAS, 2000).

A complexidade da questão ambiental está presente desde a sua definição e compreensão. A Ecologia Clássica apresenta um conceito reducionista de meio ambiente, considerando apenas os seus aspectos naturais. Freire, Nascimento e Silva (2006, p. 22) trazem a visão de Diozhkin (1983), na qual "o meio ambiente era definido como aquele que rodeia os organismos e com o qual eles entram em contato: o solo, a neve, o calor, o frio, o vento, os inimigos e parasitas, os amigos e os seres semelhantes". Diante dos impactos ambientais apresentados, percebemos que tal concepção não se sustenta, sendo necessária uma compreensão mais abrangente do que seja meio ambiente. No presente trabalho, o ambiente é entendido como natural, social, político, ecológico, econômico, cultural, estético, emocional e ético (FREIRE; NASCIMENTO; SILVA, 2006). Assim, podemos chamar de meio ambiente desde a relação do homem com o próprio homem, que na sociedade capitalista tem se caracterizado pela exploração, até a relação com o espaço construído e com o espaço natural.

As políticas para o desenvolvimento econômico e social são pautadas nos princípios capitalistas de maior extração de lucro e não consideram os impactos ambientais gerados, sua complexidade e as relações entre estes e os impactos sociais (políticos e culturais). Nesse contexto, o movimento ecológico percebe a crise ambiental como uma questão social e luta pela sua politização, compreendendo que o acesso aos recursos naturais é um direito público e universal (LIMA, 2002).

Apesar do avanço tecnológico cada vez mais acelerado, que possibilita ao homem conhecer os processos ecológicos mais profundamente (CAMPOS, 2000), não há uma preocupação da aplicabilidade desses conhecimentos em prol de uma relação harmônica e produtiva com a natureza. Do mesmo modo, não há uma preocupação com o respeito às culturas locais, aos saberes populares e não acadêmicos e às singularidades das relações de determinadas comunidades com a 
natureza e com a vida. Contudo, o princípio capitalista regente na atualidade pode não ser capaz de arcar com as conseqüências - muitas vezes irreversíveis - do brutal processo de degradação: “Apesar dos inegáveis avanços tecnológicos pós-industriais, a humanidade inicia $\mathrm{O}$ século XXI lutando, não apenas por solo, mas também por água e ar, num ambiente hostil que remonta à era pré-industrialista" (DIAS, 2000, p. 19).

Nesse cenário, surge a possibilidade de repensar certas práticas, como também certas teorias. O momento atual foi atingido por uma "crise generalizada", como afirma Grün (1996): crise de paradigmas, crise de valores, crise da ética e outras. Porém, todas essas crises podem ser compreendidas como a chamada crise ecológica, que figura como a primeira crise planetária da história.

As atuais questões ambientais não conseguem ser discutidas de acordo com os pressupostos do racionalismo cartesiano. $\mathrm{Na}$ contemporaneidade, a fragmentação das ciências não é capaz de atender a complexidade dos fenômenos:

[...] precisamos transformar, revolucionar e mudar, o que implica necessariamente em [sic] esquecer, abandonar e deixar para trás o mecanicismo reducionista [...] então precisamos de um modelo ou matriz normativa que não seja reducionista, fragmentário, sem vida e mecânico, mas que seja complexo, holístico, vivo e orgânico (GRÜN, 1996, p. 62-63).

Em Educação Ambiental, é Capra quem sustenta a necessidade de uma mudança paradigmática. Por meio de uma citação desse autor, Grün (1996) possibilita o questionamento do modelo mecanicista e insere o tema Educação Ambiental na concepção não atomista:

Sistemas vivos incluem mais que organismos individuais e suas partes. Eles incluem sistemas sociais - família ou comunidade - e também ecossistemas. Muitos organismos estão não apenas inscritos em ecossistemas, mas são eles mesmos ecossistemas complexos, contendo organismos menores que têm considerável autonomia e estão integrados harmoniosamente no todo. Todos esses organismos vivos são totalidades cuja estrutura específica surge das interações e interdependências de suas partes (CAPRA apud GRÜN, 1996, p. 64). 
A concepção sistêmica que fundamenta a Educação Ambiental permite que esta reconheça a grande importância das relações existentes entre os indivíduos em sociedade e o meio ambiente. Essa visão não atomista possibilita-nos reconhecer que o processo de construção de conhecimento e de despertar de um olhar crítico na sociedade é muito mais relevante do que um produto final focado em indivíduos isoladamente.

Dentro desse novo arcabouço teórico, a Educação Ambiental vigora na sociedade como um sistema educacional renovado, libertador. De acordo com Dias, a Educação Ambiental

teria como finalidade promover a compreensão da existência e da importância da interdependência econômica, política, social e ecológica da sociedade; proporcionar a todas as pessoas a possibilidade de adquirir conhecimentos, o sentido dos valores, o interesse ativo e as atitudes necessárias para proteger e melhorar a qualidade ambiental; induzir novas formas de conduta nos indivíduos, nos grupos sociais e na sociedade em seu conjunto, tornando-a apta para os seus problemas ambientais, como forma de elevação da qualidade de vida (DIAS, 2000, p. 83).

Essa concepção de Dias (2000) acerca da Educação Ambiental consegue traduzir em termos próprios a complexidade do elemento aqui discutido. Pensar sobre o espaço ecológico na era contemporânea demanda uma relação de troca entre sujeitos que produza conhecimentos capazes de compreender as multifaces desse fenômeno.

No entanto, o desenvolvimento da Educação Ambiental foi ocorrendo num cenário predominantemente cartesiano e agregado aos influentes valores capitalistas. Sendo assim, não foi possível isentar algumas vertentes dessa área dos princípios modernos.

Entre tais vertentes, temos a Educação Ambiental Conservadora, citada por Guimarães (2004, p. 26) como uma concepção de educação que se mostra "inapta de transformar uma realidade (a qual ela própria é um dos mecanismos de reprodução), [conservando] o movimento de constituição da realidade de acordo com os interesses dominantes - a lógica do capital". 
Guimarães (2004) afirma que a Educação Ambiental Conservadora ancora-se na visão de mundo fragmentada, em que se priorizam as transformações individuais, principalmente no âmbito das mudanças comportamentais. Tal prática compactua com o reducionismo da ciência moderna, fazendo com que se perca no processo educacional a preciosidade das relações na construção de um saber e na formação dos sujeitos. Essa vertente da Educação Ambiental acredita que a transformação social pode acontecer pela soma de ações individuais, o que desconsidera o caráter complexo do fenômeno.

Desta forma, a Educação Ambiental Conservadora tende, refletindo os paradigmas da sociedade moderna, a privilegiar ou promover: o aspecto cognitivo do processo pedagógico, acreditando que transmitindo o conhecimento correto fará com que o indivíduo compreenda a problemática ambiental e que isso vá transformar seu comportamento e a sociedade; o racionalismo sobre a emoção; sobrepor a teoria à prática; o conhecimento desvinculado da realidade; a disciplinaridade frente à transversalidade; o individualismo diante da coletividade; o local descontextualizado do global; a dimensão tecnicista frente à política; entre outros (GUIMARÃES, 2004, p. 27).

Carvalho (2004a) considera a Educação Ambiental Conservadora como detentora de uma visão ingênua de educação, que sustenta um processo educacional pela convergência de boas intenções ambientais. Dessa forma, perde-se o caráter crítico e transformador da educação e mantém-se o status quo da sociedade, o que revela que essa visão, como aponta Guimarães (2000), na verdade não é tão ingênua assim.

Nesse projeto de educação, procura-se responsabilizar os indivíduos pelos problemas ambientais, fazendo com que busquem soluções próprias. A importância dada às mudanças comportamentais tira do foco as relações de poder que ditam e mediam as relações sociais. Além disso, transpõe-se o problema ambiental para o indivíduo, como se este não tivesse nenhuma relação com a sociedade de consumo na qual está inserido (GUIMARÃES, 2000).

Superando e contrapondo-se à visão ingênua da Educação Ambiental, surge a Educação Ambiental Crítica, que se constitui como 
"uma abordagem que traz a complexidade para a compreensão e intervenção na realidade socioambiental” (GUIMARÃES, 2004, p. 28).

Carvalho (2004a) traz a importância de formar o indivíduo considerando a sua relação com o meio ambiente no qual está inserido. E mais: considerando também o seu contexto histórico, colocando-o como um ser social e implicado nesse processo.

Essa concepção da Educação Ambiental é pautada na Teoria Crítica, que, segundo Guimarães (2004, p. 17), tem como referências Paulo Freire, Milton Santos e Edgard Morin, que permitiram a "leitura crítica de um espaço complexo”. Carvalho (2004b) cita as raízes da educação crítica nos ideais democráticos e emancipatórios do pensamento crítico, o que nos remete novamente a uma das referências nessa área, Paulo Freire, que reconhece no processo educacional a possibilidade de emancipar, de construir democraticamente as alternativas desejadas (FREIRE, 1980).

É preciso que haja um processo de educação dos sujeitos para que estes percebam que o meio ambiente não é algo alheio à nossa realidade. Tudo faz parte de um só sistema, onde há vida e interdependência dos seres. Porém, a simples percepção não é suficiente. Deve haver a conscientização, que, de acordo com Freire,

consiste no desenvolvimento crítico da tomada de consciência. A conscientização implica, pois, que ultrapassemos a esfera espontânea de apreensão da realidade, para chegarmos a uma esfera crítica na qual a realidade se dá como objeto cognoscível e na qual o homem assume uma posição epistemológica (1980, p. 26).

Freire (1980) afirma ainda que a conscientização constitui um processo crescente e contínuo, em que quanto maior a conscientização/ formação do sujeito, maior a possibilidade deste de se tornar um anunciador e um denunciador diante do compromisso assumido. O importante, então, é desenvolver processos de Educação Ambiental capazes de mobilizar e sensibilizar o sujeito, promovendo a sua autonomia para atuar nos sistemas sociais de forma crítica.

Nas bases da Educação Ambiental Crítica, há uma íntima ligação com a educação popular, visto que ambas buscam romper com as relações desiguais cristalizadas na sociedade (GUIMARÃES, 2000). A educação 
popular "rompe com uma visão de educação tecnicista, difusora e repassadora de conhecimentos, convocando a assumir a mediação na construção social de conhecimentos implicados na vida dos sujeitos" (CARVALHO, 2004b, p. 18). Segundo Loureiro (2004), a Educação Ambiental, sob a consideração da perspectiva dos sujeitos sociais, possibilita uma prática pedagógica contextualizada e crítica, em que os problemas estruturais da sociedade podem ser identificados e trabalhados rumo à sua modificação.

Essa concepção de Educação Ambiental permite aos indivíduos, pela tomada de consciência crítica, o desvelamento da realidade social e, conseqüentemente, o engajamento político que visa à transformação das condições em que se figura a opressão (GUIMARÃES, 2000). É um processo que possibilita a compreensão das relações socioambientais, autorizando os sujeitos a intervir nos problemas e conflitos ambientais (CARVALHO, 2004b), bem como nas relações sociais.

Ao contestar a ética antropocêntrica, a Educação Ambiental Crítica visa a afirmar a responsabilidade do ser humano nos processos de mudança social. A superação da dicotomia entre os sujeitos/pessoas e o meio ambiente permite a integração desses elementos e o reconhecimento da importância da complementaridade nesse processo.

Uma Educação Ambiental crítica aponta para transformações radicais nas relações de produção, nas relações sociais, nas relações homem-natureza, na relação do homem com sua própria subjetividade, num processo de construção coletiva de uma ética, uma nova cultura, novos conhecimentos. Processos estes assumidos por sujeitos individuais e coletivos que desvelam a necessidade da construção de novo paradigma, um novo modelo de relacionamento com a natureza e de intervenção na história (GUIMARÃES, 2000, p. 84).

Os conteúdos apresentados neste texto nos direcionam para uma reflexão sobre o futuro que queremos e o futuro que estamos construindo. São patamares distintos, quando vistos sob a ótica da educação hegemônica e conservadora. Um deles se coloca como idealista, utópico, enquanto o outro se posiciona como concreto, real. Contudo, quando olhamos por meio das lentes de uma educação crítica e transformadora, 
essas realidades distintas se aproximam e caminham para uma confluência: confluência com a humanidade, confluência com a contemporaneidade, e é isso o que a Educação Ambiental Crítica almeja: a integração entre ideal e realidade, entre meio ambiente e sociedade.

\section{A Formação do Sujeito Ecológico}

Ao considerarmos o dinamismo relacional existente entre os indivíduos e o meio ambiente, precisamos desenvolver atitudes e adotar comportamentos com base na sustentabilidade ambiental. Carvalho (2004a, p. 177) vai além, afirmando que, para a formação de uma atitude ecológica, é preciso adotar "um sistema de crenças, valores e sensibilidades éticos e estéticos orientado segundo os ideais de vida de um sujeito ecológico [grifo nosso]".

Vale salientar que, quando ocorrem isoladamente, a adoção de alguns comportamentos e a formação de uma atitude ecológica não são capazes de formar o sujeito ecológico, tomado como um tipo ideal. "As atitudes orientam as decisões e os posicionamentos dos sujeitos no mundo". Os comportamentos "são as ações observáveis, efetivamente realizadas, e podem estar ou não de acordo com as atitudes do sujeito" (CARVALHO, 2004a, p. 177).

Tassara e Ardans (2005) afirmam que os indivíduos, nas suas relações intra e intergrupais, devem respeitar a diversidade e agir cooperativamente, compartilhando as experiências vividas de maneira associativa, de modo a historicizar os seus processos de socialização ao longo do seu desenvolvimento. Dessa maneira, emerge o sujeito histórico, complementar ao sujeito ecológico.

Diante de mais uma dimensão necessária para a formação do sujeito ecológico - a expressão do sujeito histórico -, percebemos o quanto a educação é fundamental nesse processo, proporcionando a noção de pertencimento, conforme menciona Mourão Sá:

A necessidade de associar-se a outros seria, então um aspecto indissociável da organização viva do indivíduo-sujeito. [...] [estes] se incluem em relações de pertencimento sem perder sua identidade particular, realizando simultaneamente 
a distinção individual e o pertencimento societário, a inclusão identitária e a exclusão egocêntrica (MOURÃO SÁ, 2005, p. 251).

Complementando a idéia de um sujeito histórico, faz-se necessária uma relação dialógica entre os indivíduos no mundo, possibilitando a construção de conhecimentos no processo relacional com harmonia e integralidade entre os seres.

Devemos considerar que o foco desse trabalho educativo é a formação de sujeitos capazes de exercer o seu protagonismo na sociedade. $\mathrm{O}$ despertar da consciência crítica, ressaltando-se sempre a operacionalização desse termo, apresentada por Freire (1980), permite que esses sujeitos questionem e atuem nas diversas esferas da sociedade: políticas, econômicas, sociais ou educacionais. Dessa maneira, a ética capitalista é apenas mais um aspecto a ser não só observado e criticado, mas também modificado pela participação social e pelo exercício da cidadania.

É por acreditarmos na possibilidade da formação de um sujeito ecológico, comprometido com a construção de uma sociedade sustentável, que discutiremos a potencialidade da arte, especificamente da fotografia, em trabalhos educativos que busquem formar sujeitos conscientes e críticos nas suas relações com a vida, com a sociedade e com as questões ambientais. Lembramos que estas devem ser compreendidas em toda a sua complexidade, ou seja, na sua articulação com as relações sociais de produção material e simbólica do mundo capitalista e não apenas como referência ao mundo natural e físico.

\section{Fotografia e educação ambiental: possibilidades}

\section{Recursos metodológicos em educação ambiental}

Carvalho et al. (1996, p. 78) apontam o processo educativo como uma possibilidade muito forte e presente nos diversos setores para se trabalhar as questões ambientais, sendo colocado como um "agente eficaz de transformação". O desenvolvimento desse trabalho possibilita a adoção de vários procedimentos metodológicos usados em trabalhos educativos, a 
exemplo de oficinas, dinâmicas de grupo, entre outros ${ }^{4}$. $\mathrm{O}$ uso desses recursos objetiva despertar o sujeito, inserindo-o numa prática consciente, além de se configurarem como metodologias participativas, que levam em consideração os saberes de todos aqueles implicados no processo de construção do conhecimento.

Podemos apontar como uma das dificuldades a ser trabalhadas em Educação Ambiental a necessidade da utilização de metodologias e procedimentos didáticos que sejam interdisciplinares (APA, 2006). Devido à freqüente dificuldade de estabelecer diálogo entre as diversas áreas de conhecimento, essas metodologias se apresentam muitas vezes deficientes e incapazes de refletir o espírito da Educação Ambiental.

Além disso, não só os procedimentos metodológicos, mas também os materiais didáticos e paradidáticos têm-se mostrado deficientes e, freqüentemente, não condizem com a proposta da Educação Ambiental Crítica. A título de ilustração, podemos citar a consideração de Carvalho et al. (1996) de que grande parte dos materiais com enfoque pedagógico apela apenas para a participação política no âmbito individual, contradizendo os princípios da Educação Ambiental, que apontam para a necessidade de uma atuação participativa de toda a sociedade quando se busca a solução dos problemas ambientais. Ainda para ilustrar essas deficiências, podemos mencionar as colocações de Viezzer, Rodrigues e Moreira (1996) sobre outras publicações que, também em sua maioria, desconsideram "a possibilidade de construção do saber por meio da experiência", o que, novamente, se contrapõe à Educação Ambiental, que preza o "processo de aprendizagem, intimamente ligado ao cotidiano e ao saber vivenciado" (VIEZZER; RODRIGUES; MOREIRA, 1996, p. 130).

Muitos desses materiais foram analisados na publicação Avaliando a Educação Ambiental no Brasil: materiais impressos e chegou-se à conclusão de que esses instrumentos são muito valiosos na atuação do educador, de modo que precisam ser aperfeiçoados no intuito de melhor atender o

\footnotetext{
4 Vale ressaltar que esses procedimentos não são exclusivos da Educação Ambiental. O que diferencia é o seu modo de utilização, que, na Educação Ambiental, preza sempre a atuação participativa de todos e a construção coletiva do saber.

A informação sobre a utilização desses recursos foi obtida de modo informal, por meio de diálogos com profissionais que trabalham em Universidades e Organizações Não Governamentais.
} 
público ao qual se destina. Devem ainda se adequar às informações que sejam condizentes com a proposta de cada material, pois é comum haver uma discrepância entre a forma e o conteúdo.

Carvalho et al. (1996) citam que as atividades vinculadas à Educação Ambiental, tanto na educação formal como no processo educativo não formal, foram iniciadas no Brasil por volta da década de $70 \mathrm{e}$ tiveram como resultado a produção de diversos materiais, como cartilhas, panfletos, folders, jornais, folhetos, jogos e livros didáticos e paradidáticos. Alguns desses materiais, em suas produções práticas artísticas, de acordo com Apa (2006), revelam-se importantes aliados no processo de construção do saber ambiental.

Além de estar presente nos materiais impressos, a arte é valorizada em muitos processos de formação em Educação Ambiental como um modo de ver e estar no mundo e de produzir leituras diversificadas e singulares sobre a existência, a partir do desenho, da pintura, do vídeo, da fotografia, entre outros. Enfim, todas essas modalidades artísticas propiciam/estimulam a integração dos sujeitos com o meio ambiente de forma lúdica, criativa, crítica e atraente.

\section{A Arte Despertando o Sujeito Ecológico}

A arte é uma forma de conhecimento que sempre esteve presente em nossa sociedade. Por meio dela, a humanidade foi desenvolvendo sua criatividade, formulando e expressando o seu senso estético. A expressão artística permite ao ser humano combinar pensamento, linguagem, afeto, intuição, enfim, possibilita a interação das múltiplas dimensões humanas, convergindo em uma visão mais completa do mundo no qual estamos inseridos (APA, 2006).

A expressão artística tende, naturalmente, ao pensamento do novo paradigma e às premissas da Educação Ambiental, na medida em que permite a integração de saberes e a afirmação da complexidade. Assim sendo, contrapõe-se ao modelo tradicional de educação, que compartimentaliza conhecimentos em disciplinas rígidas e incomunicáveis e separa o racional do emocional, como se este fosse inferior àquele. A arte como atividade educativa, por sua vez, busca a união de conhecimentos 
por meio de um processo dinâmico que favorece a expressão da criatividade e conduz a aprendizagens significativas (APA, 2006). Por meio da arte, é possível que os indivíduos representem simbolicamente seus conceitos e valores, favorecendo o exercício da sua imaginação, criatividade e liberdade de expressão, princípios fundamentais para a construção de conhecimentos em Educação Ambiental.

Além disso, a arte constitui uma metodologia singular em Educação Ambiental pelo seu caráter interdisciplinar, que favorece o diálogo entre disciplinas e permite a formulação de novos mecanismos metodológicos e materiais de aprendizagem. Apa (2006) pontua de forma pertinente a consonância dessa interdisciplinaridade inata da arte com os princípios de Educação Ambiental propostos pelo Ministério da Educação (MEC).

Além da possibilidade de dialogar com todos os campos de saber, a arte permite a imersão total do sujeito, fazendo com que os seus conhecimentos sejam considerados e possam fazer parte desse processo. Assim sendo, a arte prioriza práticas participativas em que o indivíduo possa utilizar toda a sua bagagem cultural na construção do saber dialogado e compartilhado por todos.

\section{O Status da Imagem no Mundo Contemporâneo}

Apa (2006) considera que a arte, principalmente por meio de mensagens visuais, facilita o processo de análise crítica dos problemas sociais. A ilustração é citada como veículo fundamental na comunicação de conteúdos para a população. Juntamente com o desenho, a fotografia é mencionada como a forma mais criativa e inteligível para se ter acesso a conhecimentos.

Para Berger (1999), a arte tem o poder de despertar os sentidos, principalmente a visão, devido à sua estética, que atrai os indivíduos como num passe de mágica, e devido ao fato de que ver precede toda e qualquer palavra.

Barthes (1984) afirma que as sociedades ditas "avançadas", atualmente, deixaram de consumir crenças (como as sociedades do passado) para consumir imagens. Por conta disso, passam a ser mais 
liberais, menos fanáticas, mas se tornam menos autênticas: “[...] hoje em dia as imagens são mais vivas que as pessoas. Uma das marcas de nosso mundo talvez seja essa inversão: vivemos segundo um imaginário generalizado. [...] tudo aí se transforma em imagens: só existem, só se produzem e só se consomem imagens" (BARTHES, 1984, p. 173).

Conforme Justo (2003), diante dessa disseminação imagética, o nosso olhar encontra-se trivial, habituado com o seu limiar rebaixado, dificultando a aproximação e o distanciamento necessários para o exercício de um olhar crítico perante as imagens. Essa autora aborda brilhantemente essa "indiferença" instalada em muitos sujeitos sociais: “[...] vivemos tempos de retinas fatigadas, de olhos que não vêem. A exposição maciça e veloz de imagens aos nossos olhos apressados, no mundo contemporâneo, banaliza o olhar" (JUSTO, 2003, p. 36).

Toda essa trivialidade nos distancia do significado inicial atribuído às imagens. De acordo com Berger (1999), estas foram feitas, a princípio, no intuito de evocar as aparências de algo que estava ausente. As imagens estabeleceram-se para relacionar os indivíduos com o mundo, o que foi possível, segundo Aumont (2004), de três formas:

- modo simbólico (mais especificamente símbolos religiosos): os sujeitos buscavam ter acesso ao sagrado e usavam as imagens para fazer essa representação;

- modo epistêmico: considera que as imagens trazem informações diversas sobre o mundo, permitindo que este seja conhecido pelos sujeitos, inclusive em seus aspectos não visuais. "A natureza dessa informação varia [...], mas essa função geral de conbecimento foi também muito cedo atribuída às imagens" (AUMONT, 2004, p. 80);

- modo estético: essa função tem o intuito de agradar os espectadores oferecendo-lhes sensações específicas. A estética revela-se, muitas vezes, indissociável da representação atual da arte na sociedade, o que causa uma confusão entre as duas, de modo que uma imagem com princípios meramente estéticos pode se passar por imagem artística.

Todos esses modos de apresentação da imagem apontam para a sua principal função, que é "garantir, reforçar, reafirmar e explicitar nossa relação com o mundo visual: ela desempenha papel de descoberta do visual" (AUMONT, 2004, p. 81). 
Esse processo de descoberta requer a consideração de duas experiências que são inseparáveis: uma ligada ao funcionamento orgânico e outra ligada ao contexto sociocultural. Dessa forma, cria-se uma relação entre imagens mentais e imagens reais, fazendo com que estas últimas favoreçam uma aproximação da "representação imagética da noção de mundo de determinada cultura, por conter valores inerentes nos aspectos de sua produção e de sua conseqüente significação" (TACCA, 2005, p. 12). Com isso, as variantes culturais são consideradas importantes na determinação dos padrões perceptivos e influenciam a construção de conhecimento da realidade a partir da imagem.

A imagem técnica foi uma busca constante no final do século XVIII e início do século XIX e desde então muitos aparelhos foram inventados, inclusive os que fixavam uma imagem realista, automática e reprodutível. Assim, a fotografia ganha a sua identidade e configura-se como a "primeira onda da globalização de imagem" (TACCA, 2005, p. 10).

Segundo Berger (1999), a imagem é considerada uma cena que pode ter sido criada ou reproduzida, incorporando um modo de ver. Logo, considera-se aquele que produz ou registra uma imagem como um ator importante nesse processo, o que nem sempre foi assim, especialmente na fotografia,

porque [esta] não [é], como se presume freqüentemente, um registro mecânico. Cada vez que olhamos uma fotografia estamos cientes, por mais superficialmente que seja, do fotógrafo selecionando aquela cena entre uma infinidade de outras possíveis. [...] O modo de ver do fotógrafo é reconstituído pelas marcas que ele faz na tela ou no papel. Contudo, embora toda imagem incorpore uma maneira de ver, nossa percepção ou apreciação de uma imagem depende também de nosso próprio modo de ver (BERGER, 1999, p. 12).

Essa idéia sustentada pelo citado autor nos remete a uma consideração de Aumont (2004), que afirma ser o espectador um parceiro ativo da imagem em seus aspectos afetivos e cognitivos. Logo, ao considerarmos uma imagem, devemos sempre lembrar que nela estão embutidas diversas formas de perceber o mundo. Firma-se um "diálogo de olhares", uma busca de reciprocidade que, para Berger (1999), é mais 
fundamental do que o diálogo falado. A sensação de que podemos ver faz com que atentemos para a possibilidade de sermos vistos e assim caímos no admirável mundo imagético!

E nesse mundo novo é importante que consideremos a influência exercida pelas imagens sobre os sujeitos, visto que, de acordo com Berger (1999), nunca houve historicamente tamanha concentração de mensagens visuais na sociedade como há atualmente na era publicitária.

\section{A Fotografia revelando a arte da Educação Ambiental}

No diversificado universo das imagens, a fotografia adquiriu um status diferenciado, oferecendo de forma direta um testemunho acerca do mundo que nos rodeia e das pessoas e coisas nele inseridas. A invenção da câmera fotográfica modificou a forma como a humanidade via o mundo, alterou o seu significado, ou melhor, multiplicou e fragmentou muitos significados do real (BERGER, 1999).

No espectro das imagens fotográficas, Barthes (1984) afirma que podemos assumir três papéis distintos: o que registra a imagem (operator), o que olha a imagem (spectator) e o que é fotografado, aquele que se torna imagem (spectrum). Este último, por sua vez, ao representar um espetáculo, como diz o significado literal da palavra, garante a unicidade do processo fotográfico, em que a cena reproduzida jamais poderá se repetir existencialmente.

Mesmo diante de tanta beleza emitida pela câmera escura em todo o seu processo, a fotografia, de acordo com Justo (2003), é uma forma de apreensão do outro pouco valorizada. É um olhar que se contrapõe ao imediatismo da sociedade atual. Permite ao sujeito estar diante de um mesmo fenômeno por tempo indeterminado de maneira a senti-lo, percebê-lo, julgá-lo, interpretá-lo. Um estudo realizado pelo Centro de Estudos e Pesquisas em Educação, Cultura e Ação Comunitária complementa a caracterização da fotografia:

[...] exerce um fascínio sobre todos nós, uma vez que ela oferece a possibilidade de captar aquilo que estamos vendo de maneira instantânea, sem que precisemos nos esforçar muito para isso [...]. No entanto, ao refletirmos mais detalhadamente 
sobre o que é uma fotografia, percebemos que a semelhança que ela apresenta em relação à realidade é bastante ilusória... Afinal de contas, mais do que a semelhança com aquilo que foi visto, o importante em uma imagem é que ela seja capaz de expressar algo, oferecendo um vislumbre da nossa maneira de ver as coisas, transmitindo um pouco de nossos sentimentos diante do impacto que a visão do mundo causa em nós (CENPEC, 1998b apud JUSTO, 2003, p. 36).

Essa citação traz consigo uma evolução conceitual, já que, em suas primeiras expressões e conceitos, a fotografia colocava-se como uma verdade imagética, vista muitas vezes como a própria realidade pura e neutra, sem a consideração dos valores e princípios daquele que observa a imagem. Quando Justo (2003) destaca o caráter ilusório de representação do real na fotografia, ela explicita que esta é apenas um instrumento e que a construção de um saber que toma por base uma imagem vai além da sua representação, necessitando da articulação entre o olhar do sujeito individual e o sujeito cultural.

É preciso que essa modalidade artística seja conectada a ações que, de fato, diante desse impacto gerado nos sujeitos, sejam capazes de transformar, de ressignificar a experiência. Destarte, torna-se clara a importância da utilização da fotografia em um processo educacional que compartilhe uma forma de ver o humano e as suas relações como ferramentas essenciais nesse processo de transformação social, como propõe a Educação Ambiental em sua abordagem crítica.

Apesar da consideração da dimensão artística na Educação Ambiental como um todo, Apa (2006) refere-se em seu trabalho apenas à pintura e ao desenho, restringindo o campo artístico a essas áreas, o que é bastante comum, por sinal. Uma das propostas do presente estudo é ampliar esse campo visual trazendo como possibilidade de instrumento metodológico em Educação Ambiental a fotografia, ainda pouco trabalhada em Educação, porém, bastante empregada em estudos antropológicos.

A fotografia é utilizada no campo das ciências humanas com o objetivo principal de atribuir significado à imagem. As informações encontradas nas imagens fotográficas favorecem o enriquecimento da 
compreensão dos sujeitos, o que constitui uma grande vantagem desse método (NEIVA-SILVA; KOLLER, 2002).

Tais ações podem ser do escopo da Educação Ambiental, pois o contato com a fotografia pode permitir que coisas esquecidas ou nunca vistas sejam percebidas, educando o sujeito para a imaginação e para um olhar multifacetado que vai além da imagem cristalizada que se tem naquele momento.

A gravidade da questão ambiental solicita, conforme pontua Justo (2003, p. 181) ao discutir a potencialidade da fotografia para o trabalho educativo, que se exercite um olhar mais atento para aquilo que nos rodeia. "A fotografia pode apontar reflexões parciais, ajuda a perguntar e ser provocadora de alguns questionamentos". Desse modo, é possível que os sujeitos passem a se implicar nesse olhar e se conscientizem, como pontua Freire (1980), de que todos estão inseridos na problemática ambiental.

A utilização da fotografia no processo educativo pode fazer com que a percepção da imagem capturada expresse mais do que apenas a sua estética. É possível que a fotografia permita que o sujeito seja conduzido a novas linguagens, inclusive à dimensão política dos fenômenos representados, visto que o conteúdo daquele enquadramento não se traduz em sentidos que impressionam, que causam ruídos na comunicação, mas fornece detalhes que constituem o próprio saber na sua essência (BARTHES, 1984).

O referido autor complementa essa afirmação ao colocar que a fotografia chega a ser subversiva quando influencia a reflexão. Além disso, Barthes (1984, p. 48) a coloca como perigosa quando assume determinadas funções, tais como "informar, representar, surpreender, fazer significar".

Quando pensamos na fotografia em Educação Ambiental, consideramos todas essas funções apresentadas por Barthes (1984) e consideramos que essa significação pode ser a produção de um saber coletivo, que considera a visão de mundo do outro como fundamental para a edificação desse saber. Quando o sujeito captura uma imagem, esta, por sua vez, ressoa de algum modo nesse indivíduo. A colocação do significado dessa imagem no processo educativo permite que haja um acesso mútuo aos conhecimentos, e aquilo que o outro me diz contribui para a minha formação. A consideração dos aspectos socioambientais que caracterizam 
um dado espaço possibilita que conteúdos teóricos sejam abordados a partir de uma referida realidade, mostrando ao outro que a sua participação é mais do que fundamental para a construção desse conhecimento, corroborando o princípio da participação presente na Educação Ambiental.

Barthes (1984) faz menção a dois conteúdos presentes em uma fotografia que merecem ser aqui considerados: o studium e o punctum. $\mathrm{O}$ primeiro refere-se aos aspectos culturais da foto. Faz-se notável quando o observador consegue compreender a real intenção do fotógrafo quando capturou aquela imagem. Já o punctum está diretamente ligado ao observador e ao sentimento que a imagem capturada suscita nele. É um conteúdo acrescentado à foto, mas que já está presente nela. É aquilo que a foto traz consigo e que punge o sujeito, retirando-o, como menciona Barthes (1984, p. 84-85), "de seu blábláblá [sic] costumeiro: 'Técnica', 'Realidade', 'Reportagem', 'Arte', etc. [isso seria o studium]: nada a dizer, fechar os olhos, deixar o detalhe remontar sozinho à consciência afetiva". É a percepção que alguém tem do imperceptível aos olhos do outro.

A consideração desse outro e do olhar que ele dispensa a um dado fenômeno, além de favorecer a sua participação no processo educativo, permite que o sujeito sinta-se pertencente não só a esse trabalho, mas também a esse lugar de onde ele vem, remetendo-o à noção de pertencimento, na medida em que favorece a ampliação de sua consciência sobre o real vivido. O trabalho com grupos, quando se fala de fotografia, pode favorecer a consideração do sujeito e de suas concepções na dimensão subjetiva e social. Olhar imagens e ressignificá-las dentro de um grupo necessita de um respeito à diversidade e de uma ação cooperativa. $\mathrm{O}$ pertencer exige uma inclusão identitária e também uma exclusão egocêntrica; devemos nos unir e separar-nos do meio para favorecer o exercício da alteridade e possibilitar uma relação dialógica entre os sujeitos e o meio ambiente.

Justo (2003) afirma que uma oficina de fotografia e a disponibilidade para se trabalhar a noção de pertencimento do grupo facilitam a escuta entre os participantes e permitem que eles desenvolvam o olhar. Além disso, possibilitam a apreensão da visão de mundo dos sujeitos, das suas representações sobre um dado fenômeno e suscitam um 
espaço para o compartilhamento desses olhares, direcionando os indivíduos para o respeito dos diferentes pontos de vista.

Esse sentimento de pertença é muito importante nos trabalhos em Educação Ambiental, pois diz respeito tanto ao grupo de trabalho quanto à comunidade em que o sujeito está inserido (a qual pode ser retratada pela fotografia). Esse pertencimento imprime no sujeito a sensação de organicidade fundamental para que haja uma percepção da dimensão dos problemas socioambientais. Assim sendo, é possível que esse pertencimento estenda-se da comunidade local para a comunidade global e, desse modo, revele ao sujeito a importância do pensar global e agir local para contribuir no processo de transformação social.

Em nossa sociedade, a educação pode direcionar os sujeitos para um mundo de reprodução de saber e aceitação do padrão social dominante. Contrapondo-se a esse modelo, a Educação Ambiental propõe algo que podemos nomear de revolução, na medida em que pode impulsionar os indivíduos a sair dessa posição de inércia e aceitação incondicional do sistema para propor o novo. Da mesma forma que temos esses dois referenciais de mundo e esses dois modelos educacionais, temos também duas formas de ver a fotografia: esta pode ser louca ou sensata, como propõe Barthes (1984).

Quando consideramos a sensatez da fotografia, permanecemos no relativismo do realismo, amarrados por hábitos empíricos ou estéticos. Por outro lado, quando aceitamos a fotografia como extensão da loucura, acreditamos na integralidade desse realismo e na sua originalidade, com a possibilidade de inverter o curso das coisas, o que Barthes (1984, p. 175) nomeou de "êxtase fotográfico".

Assim como podemos escolher uma dessas vias da fotografia propostas por Barthes (1984, p. 175), podemos escolher também a Educação que queremos: aquela que submete o "seu espetáculo ao código civilizado das ilusões perfeitas" ou a que afronta o "despertar da intratável realidade".

E ao nos referirmos à questão ambiental e à sua visão crítica da educação, precisamos de uma educação que nos tire do mundo das ilusões. Convergimos então para a aceitação daquilo que é nomeado como loucura. Se o normal é andar em consonância com a sociedade atual, sem 
questionar os seus princípios e práticas e como isso reflete no meio ambiente, então sugerimos a aceitação da loucura que há em nós, de forma incondicional, para que possamos, de fato, inverter a ordem das coisas e alcançar um "êxtase fotográfico" que seja impulsionador do princípio da transformação.

\section{Referências}

AUMONT, Jacques. A parte do espectador. In: Papirus, 2004. Cap. 2, p. 77-96. - A Imagem. 9. ed. São Paulo:

APA, Hatsi Corrêa Galvão do Rio. A utilização da arte como ferramenta para educação ambiental. Universidade Federal de Santa Catarina - UFSC, Departamento de Zootecnia e Desenvolvimento Rural, Disciplina de Projetos e Seminários. Santa Catarina, 2006. Disponível em: <http://www.cca.ufsc.br/Projetos/Hatsi\%20C.\%20G.\%20Do\%20Rio\%20Apa\%2020052.pdf>. Acesso em: 10 set. 2006.

BARTHES, Roland. A Câmara Clara: nota sobre fotografia. Tradução de Júlio Castañon Guimarães. Rio de Janeiro: Nova Fronteira, 1984.

BERGER, John. Modos de Ver. Tradução de Lúcia Olinto. Rio de Janeiro: Rocco, 1999.

CAMPOS, Marília Menezes Freitas de. Educação Ambiental e paradigmas de interpretação da realidade: tendências reveladas. Campinas: [s.n.], 2000. Disponível em: $<$ http:/ /libdigi.unicamp.br/ document/?view=vtls000206271>. Acesso em: 21 abr. 2006.

CARVALHO, Isabel Cristina de Moura. Educação ambiental: a formação do sujeito ecológico. São Paulo: Cortez, 2004a.

Educação ambiental crítica: nomes e endereçamentos da educação. In: LAYRARGUES, Philippe Pomier (Org.). Identidades da educaşão ambiental brasileira. Brasília: Ministério do Meio Ambiente, 2004b. p. 13-24.

CARVALHO, Luiz Marcelo de et al. Enfoque pedagógico: conceitos, valores e participação política. In: TRAJBER, Rachel; MANZOCHI, Lúcia Helena (Org.). Avaliando a Educação Ambiental no Brasil: materiais impressos. São Paulo: Gaia, 1996. p. 77-120.

DIAS, Genebaldo Freire. Educação ambiental: princípios e práticas. 8. ed. São Paulo: Gaia, 2000.

FREIRE, Jamile Trindade; NASCIMENTO, Maria de Fátima Falcão; SILVA, Sueli Almuiña Holmer. Diretrizes Curriculares de Educação Ambiental para Professores da Rede Municipal de Ensino de Salvador. Salvador: Secretaria Municipal da Educação e Cultura, 2006.

FREIRE, Paulo. Conscientização: teoria e prática da libertação; uma introdução ao pensamento de Paulo Freire. 3. ed. São Paulo: Moraes, 1980. 
GONÇALVES, Carlos Walter Porto. Os (des)caminhos do meio ambiente. 7. ed. São Paulo: Contexto, 2000.

GRÜN, Mauro. Ética e educação ambiental: a conexão necessária. Campinas: Papirus, 1996.

GUIMARÃES, Mauro. Educação ambiental: no consenso um embate? Campinas: Papirus, 2000.

Educação ambiental crítica. In: LAYRARGUES, Philippe Pomier (Org.). Identidades da educação ambiental brasileira. Brasília: Ministério do Meio Ambiente, 2004. p. 2534.

JUSTO, Carmen Sílvia Sanches. Os meninos fotógrafos e os educadores: viver na rua e no Projeto Casa. São Paulo: UNESP, 2003.

LIMA, Gustavo Ferreira da Costa. Crise ambiental, educação e cidadania: os desafios da sustentabilidade emancipatória. In: LOUREIRO, Carlos Frederico Bernardo; LAYRARGUES, Philippe Pomier; CASTRO, Ronaldo Souza de (Org.). Educação Ambiental: repensando o espaço da cidadania. São Paulo: Cortez, 2002. p. 109-142.

LOUREIRO, Carlos Frederico Bernardo. Educar, participar e transformar em educação ambiental. Revista Brasileira de Educação Ambiental, Brasília, n. 0, p. 13-20, nov. 2004.

MOURÃO SÁ, Laís. Pertencimento. In: FERRARO JÚNIOR, Luiz Antonio (Org.). Encontros e Caminhos: formação de educadoras(es) ambientais e coletivos educadores. Brasília: MMA, Diretoria de Educação Ambiental, 2005. p. 245-256.

NEIVA-SILVA, Lucas; KOLLER, Sílvia Helena. O uso da fotografia na pesquisa em Psicologia. Estudos de Psicologia, Natal, v. 7, n. 2, jul./dez. 2002, p. 237-250. Disponível em: $<$ http://test.scielo.br/scielo.php?script=sci_arttext\&pid=S1413-94X2002000200005\&lng $=$ pt\&nrm=iso $>$. Acesso em: 21 abr. 2006.

TACCA, Fernando de. Imagem fotográfica: aparelho, representação e significação. Psicologia e Sociedade, São Paulo, v. 17, n. 3, p. 9-17, 2005. Disponível em: <http://www.scielo.br/ pdf/psoc/v17n3/a02v17n3.pdf>. Acesso em: 20 ago. 2006.

TASSARA, Eda Terezinha de Oliveira; ARDANS, Omar. Intervenção psicossocial: desvendando o sujeito histórico e desvelando os fundamentos da educação ambiental crítica. In: FERRARO JÚNIOR, Luiz Antonio (Org.). Encontros e Caminhos: formação de educadoras(es) ambientais e coletivos educadores. Brasília: MMA, Diretoria de Educação Ambiental, 2005. p. 201-216.

VIEZZER, Moema; RODRIGUES, Carlos; MOREIRA, Tereza. Enfoque de educação popular e de gênero: "somos todos sujeitos e não objetos...". In: TRAJBER, Rachel; MANZOCHI, Lúcia Helena (Org.). Avaliando a Educação Ambiental no Brasil: materiais impressos. São Paulo: Gaia, 1996. p. 121-152.

Artigo: recebido em 18/08/2008 - aprovado em 22/12/2008 